\title{
Formation of Bone-Like Apatite on Polymeric Surfaces Modified with $-\mathrm{SO}_{3} \mathrm{H}$ Groups
}

\author{
I.B. Leonor ${ }^{1,2,3, a}$, H.-M. Kim ${ }^{4}$, F. Balas ${ }^{3}$, M. Kawashita ${ }^{3}$, R.L. Reis ${ }^{1,2}$, T. Kokubo ${ }^{5}$, \\ T. Nakamura ${ }^{6}$ \\ ${ }^{1}$ 3B's Research Group-Biomaterials, Biodegradables and Biomimetics, Univ. of Minho, \\ Campus de Gualtar, 4710-057 Braga, Portugal \\ ${ }^{2}$ Dept. of Polymer Engineering, Univ. of Minho, Campus de Azurem, 4800-058 Guimarães, \\ Portugal \\ ${ }^{3}$ Dept. of Material Chemistry, Graduate School of Engineering, Kyoto Univ., Yoshida, \\ Sakyo-ku, Kyoto 606-8501, Japan \\ ${ }^{4}$ Dept. of Ceramic Engineering, School of Advanced Materials Engineering, Yonsei Univ., \\ Seoul 120-749, Korea \\ ${ }^{5}$ Research Institute for Science and Technology, Chubu Univ., 1200 Matsumoto-cho, \\ Kasugai-shi, Aichi 487-8501 Japan \\ ${ }^{6}$ Dept. of Orthopaedic Surgery, Faculty of Medicine, Kyoto Univ., Sakyo-ku, Kyoto \\ 606-8506, Japan \\ abelinha@dep.uminho.pt
}

Keywords: Polymer; Sulfonic groups $\left(-\mathrm{SO}_{3} \mathrm{H}\right)$; Surface modification; Apatite; Simulated body fluid (SBF); Bioactivity.

\begin{abstract}
Sulfonic groups $\left(-\mathrm{SO}_{3} \mathrm{H}\right)$ were covalently attached on different polymeric surfaces enabling them to induce apatite nucleation, for developing bioactive apatite-polymer composites with a bonelike 3-dimensional structure. High molecular weight polyethylene (HMWPE) and ethylene-co-vinyl alcohol co-polymer $(\mathrm{EVOH})$ were used. The polymers were soaked in two types of sulphate-containing solutions with different concentrations, sulphuric acid $\left(\mathrm{H}_{2} \mathrm{SO}_{4}\right)$ and chlorosulfonic acid $\left(\mathrm{ClSO}_{3} \mathrm{H}\right)$. To incorporate calcium ions into to the sulfonated polymers, the samples were soaked in a saturated $\mathrm{Ca}(\mathrm{OH})_{2}$ solution for 24 hours. After soaking of the samples in a simulated body fluid (SBF), formation of an apatite layer on both surfaces was observed. The results obtained prove the validity of the proposed concept and show that the $-\mathrm{SO}_{3} \mathrm{H}$ groups are effective on inducing apatite nucleation on the surface of these polymers.
\end{abstract}

\section{Introduction}

In the last years it has been demonstrated that several functional groups, such as $\mathrm{Si}-\mathrm{OH}, \mathrm{Ti}-\mathrm{OH}$, $\mathrm{Zr}-\mathrm{OH}$, Ta-OH and $\mathrm{Nb}-\mathrm{OH}$, when incorporated onto the surface of biomaterial, can induce apatite formation on its surface, which prove that these groups are effective to induce apatite nucleation [1]. Some of these functional groups are more easily incorporated onto metal surfaces than onto polymer ones. Therefore, there is a necessity to find new functional groups that can be efficient at inducing in situ formation of apatite layer on polymeric biomaterials.

Polymeric materials have mechanical advantage over metal implants and bioactive ceramics due to their low stiffness (that will avoid stress-shielding). Therefore, if a functional group effective at inducing the apatite nucleation can be incorporated onto the organic polymer surface, inorganic apatite-organic polymer composites can be then synthesised with structure and mechanical properties analogous to those of natural bone. Among these functional groups, the incorporation of $-\mathrm{SO}_{3} \mathrm{H}$ groups onto polymer surfaces has been found valuable for biomedical applications and useful in 
terms of enhancing blood compatibility of polymeric materials [2-4]. Furthermore, some studies [3, 4] have revealed that sulfonate and sulfoxide-containing substrates lead to a much better cell proliferation than even the hydroxyl-functionalized surface. It is also well known that one of the essential requirements for an artificial material to bond to living bone is the formation of a bonelike apatite layer on its surface when it is implanted in the body. Regarding these facts, it is thought that incorporation of $-\mathrm{SO}_{3} \mathrm{H}$ groups onto biocompatible polymeric substrates can be an effective way to prepare materials with biomedical applications with improved biological features. This study addresses itself to the incorporation of $-\mathrm{SO}_{3} \mathrm{H}$ groups onto biocompatible polymeric surfaces and investigates their effectiveness at inducing apatite layer in physiological environment. Sulfonation procedures on polymer surfaces were carried out in mild conditions to avoid significant changes in the bulk properties of the substrates. The main goal in this approach is to incorporate sulfonic groups $\left(-\mathrm{SO}_{3} \mathrm{H}\right)$ onto polymeric surfaces that are not bioactive by themselves.

\section{Methods}

Two types of materials were used as substrates in the present study: (i) high molecular weight polyethylene (HMWPE, Hostalen ${ }^{\circledR}$ GM 9255F, Hoechst, Germany) and (ii) ethylene-vinyl alcohol co-polymer (EVOH, Kuraray Co. Ltd., Japan, ethylene content, 32\%-mol). EVOH substrates were obtained by hot compression moulding and HMWPE substrates were obtained by conventional injection moulding in order to produce plates. Then, the substrates were cut into specimens of 10x10x1 $\mathrm{mm}^{3}$ in size. All substrates were polished with $4 \mu \mathrm{m}$ diamond paste, ultrasonically washed with distilled water, and dried at $40^{\circ} \mathrm{C}$ for $24 \mathrm{~h}$. Sulfonation was carried out by heterogeneous reaction in two types of diluted solutions: (i) chlorosulfonic acid $\left(\mathrm{ClSO}_{3} \mathrm{H}, 50 \mathrm{vol} \%\right)$ and (ii) sulfuric acid $\left(\mathrm{H}_{2} \mathrm{SO}_{4}, 20\right.$ vol\%). The samples were immersed in $5 \mathrm{ml}$ of $\mathrm{ClSO}_{3} \mathrm{H}$ and $\mathrm{H}_{2} \mathrm{SO}_{4}$ solutions for $10 \mathrm{~min}$ and 24 hours at $40^{\circ} \mathrm{C}$ and $120 \mathrm{rpm}$. After the sulfonation, the samples were immediately soaked in $\mathrm{Ca}(\mathrm{OH})_{2}(6.7 \mathrm{mM})$ saturated solution for 24 hours at $40^{\circ} \mathrm{C}$ and $120 \mathrm{rpm}$. After this treatment, the samples were washed with distilled water. Then, sulfonated and $\mathrm{Ca}(\mathrm{OH})_{2}$-treated samples were soaked in a simulated body fluid (SBF) [5] with ion concentrations $\left(\mathrm{Na}^{+} 142.0, \mathrm{~K}^{+} 5.0, \mathrm{Ca}^{2+} 2.5, \mathrm{Mg}^{2+}\right.$ 1.5, $\mathrm{Cl}^{-} 147.8, \mathrm{HCO}_{3}{ }^{-} 4.2, \mathrm{HPO}_{4}{ }^{2-} 1.0, \mathrm{SO}_{4}{ }^{2-} 0.5 \mathrm{mM}$ ) nearly equal to those of the human blood plasma, at $36.5^{\circ} \mathrm{C}$ and $\mathrm{pH}=7.40$ for several periods up to 7 days. After soaking, the samples were washed gently with distilled water and dried at $40^{\circ} \mathrm{C}$ for 24 hours. The samples were analysed by thin-film X-ray diffraction (TF-XRD), Fourier transform attenuated total reflectance infrared spectroscopy (FTIR), field-emission scanning electron microscopy (FE-SEM) and energy dispersive $\mathrm{X}$-ray spectroscopy (EDS).

\section{Results and Discussion}

After the sulfonation treatment the hydration of HMWPE surface was observed in the FTIR spectra (not shown) by the detection of a wide $\mathrm{OH}$ stretching band, involving both the presence of $\mathrm{S}-\mathrm{OH}$ groups and absorbed water. Also, reflection bands at 1200 and $1050 \mathrm{~cm}^{-1}$ were detected for both polymers which are attributed to the asymmetric and symmetric stretching modes of $-\mathrm{SO}_{3} \mathrm{H}$ groups [6]. After $\mathrm{Ca}(\mathrm{OH})_{2}$ treatment and the subsequent soaking in SBF for 7 days, the presence of phosphate $\left(\mathrm{PO}_{4}{ }^{3-}\right)$ and carbonate $\left(\mathrm{CO}_{3}{ }^{2-}\right)$ groups was detected.

In the TF-XRD patterns of the surface of both polymer samples after soaking in SBF for several periods (using non-immersed samples as controls), several diffraction peaks assigned to an apatite-like phase (ASTM JCPDS 9-432) were observed in the Figure $1 \mathrm{~b}$ and d. Intensities of apatite phase increase as the soaking time in SBF increases (Figs. $1 \mathrm{~b}$ and d). The EVOH samples undergo several surface changes after sulfonation and $\mathrm{Ca}(\mathrm{OH})_{2}$ treatment that involved nucleation of poorly-crystalline calcium sulfate $\left(\mathrm{CaSO}_{4} \cdot 2 \mathrm{H}_{2} \mathrm{O}\right.$, ASTM JCPDS 21-816) (See the Figure 1d). 
It is worthy noting that specimens soaked in SBF just after sulfonation are not able to induce apatite nucleation (Figures $1 \mathrm{a}$ and c). This fact suggests the significance of $\mathrm{Ca}(\mathrm{OH})_{2}$ treatment on apatite-forming ability in the SBF of the $-\mathrm{SO}_{3} \mathrm{H}$ groups deposited on polymer specimens. However, the crystalline structure of HMWPE and EVOH remained unchanged after sulfonation, (Figs. $1 \mathrm{a}$ and c).
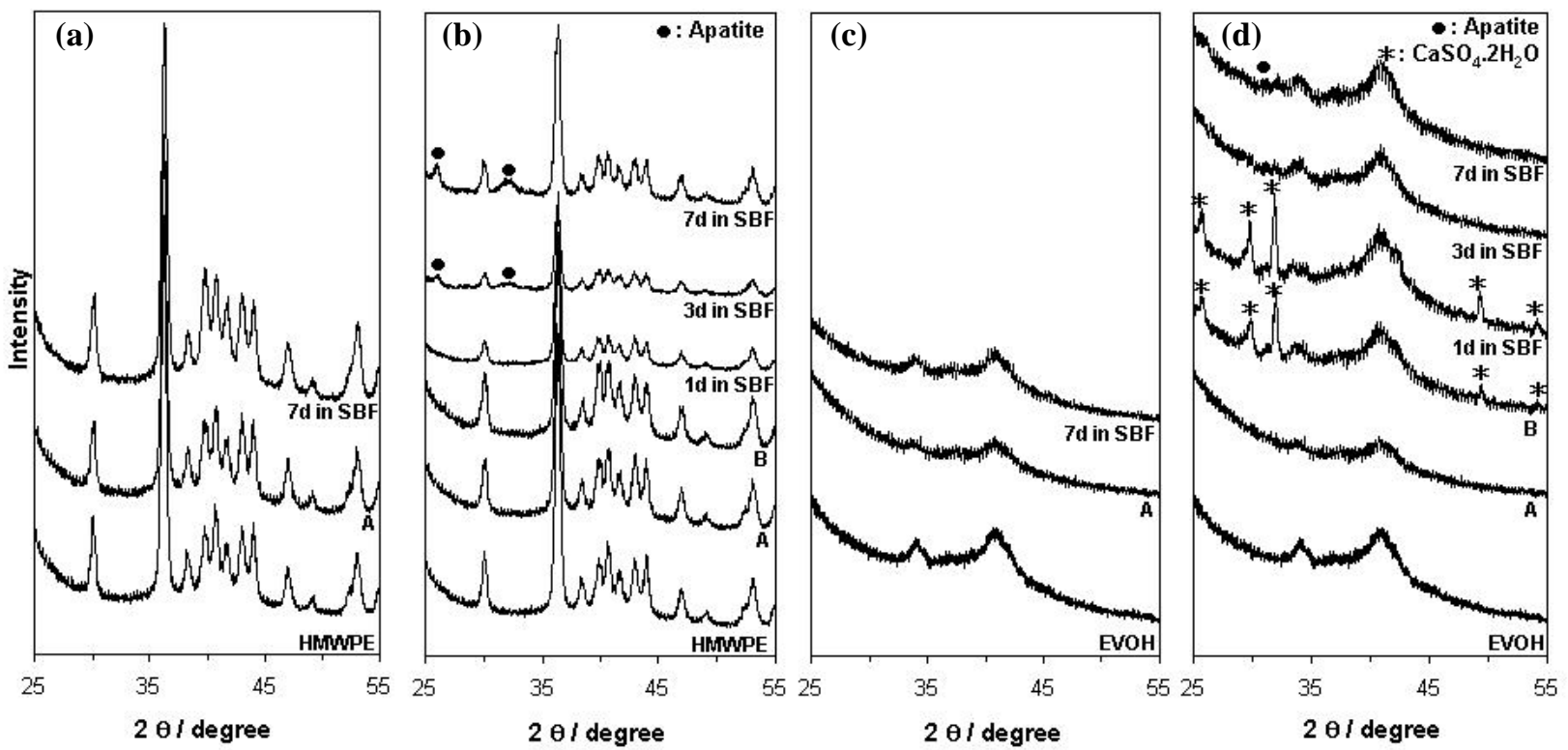

Figure 1. TF-XRD patterns of the surfaces of HMWPE and EVOH, which were subjected to the sulfonation treatment (A), to the subsequent $\mathrm{Ca}(\mathrm{OH})_{2}$ treatment $(\mathrm{B})$, and after soaking in SBF for different times.

Figures 2 and 3 shows the FE-SEM micrographs of HMWPE and EVOH substrates before and after sulfonation, $\mathrm{Ca}(\mathrm{OH})_{2}$ treatment and the subsequent soaking in SBF for 7 days.
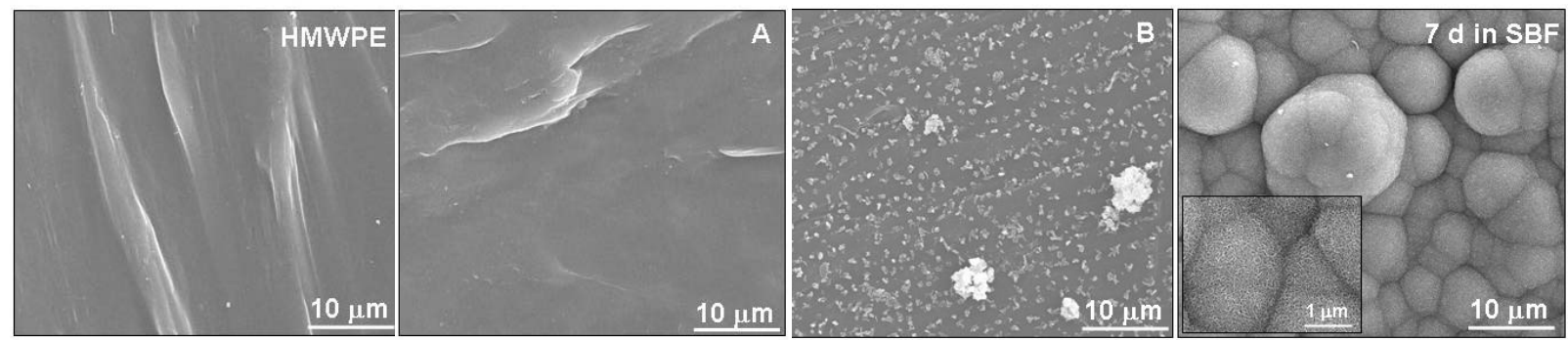

Figure 2. FE-SEM micrographs of the surfaces of HMWPE, which were subjected to the sulfonation treatment (A), to the subsequent $\mathrm{Ca}(\mathrm{OH})_{2}$ treatment $(\mathrm{B})$, and after soaking in SBF for 7 days.

It is important to mention that after the sulfonation procedure there was no evidence of any degradation of the polymers (Figs. $2 \mathrm{~A}$ and $3 \mathrm{~A}$ ), that was also confirmed by the TF-XRD analyses. This confirms that the sulfonation reactions merely transform the chemical composition and the structure of the outer surface layer, maintaining unaltered the substrate's bulk properties. After the $\mathrm{Ca}(\mathrm{OH})_{2}$ treatment, particles were spread over the polymer surface (Figure 2B), which by EDS analysis indicated a presence of calcium $\left(\mathrm{Ca}^{2+}\right)$ in the surface. For EVOH it was also detected the presence of $\mathrm{Ca}^{2+}$ that is in good agreement with the detection of calcium sulfate $\left(\mathrm{CaSO}_{4} \cdot 2 \mathrm{H}_{2} \mathrm{O}\right)$ in TF-XRD pattern (See the Figure1d).

HMWPE sulfonated surface was completely covered with an apatite layer after the $\mathrm{Ca}(\mathrm{OH})_{2}$ treatment and the subsequent soaking in SBF for 7 days (Figure 2). However, apatite layer was 
detected only after 3 days of immersion in SBF. As the immersion time in SBF increased, this layer became more dense and compact. At higher magnifications these films evidenced a finer structure, where needle-like crystals were agglomerated.

In the case of EVOH, 7 days in SBF was required to observe the formation of a dense apatite layer (Figure 3). Once more, this apatite layer showed a finer structure in such layers where needle-like crystals are agglomerated.

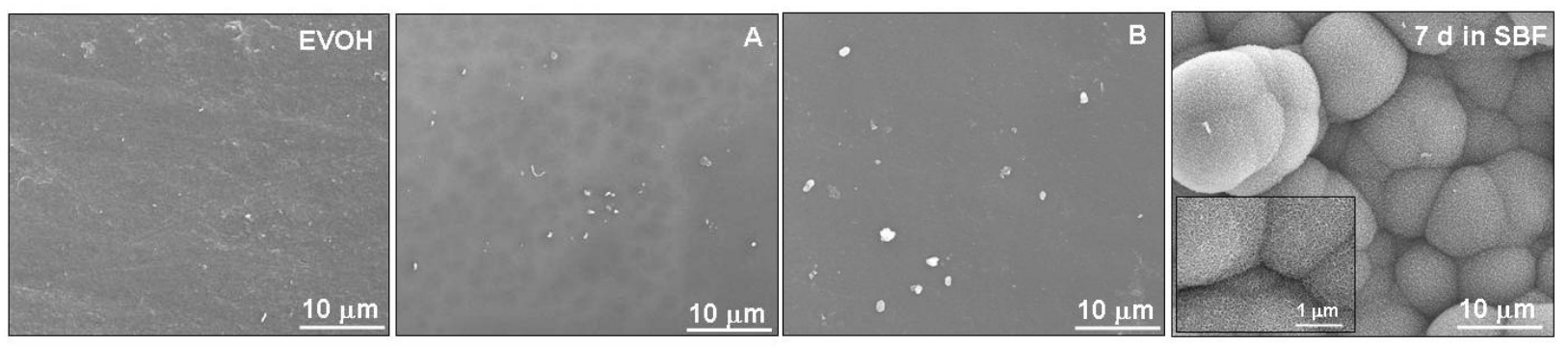

Figure 3. FE-SEM micrographs of the surfaces of EVOH, which were subjected to the sulfonation treatment (A), to the subsequent $\mathrm{Ca}(\mathrm{OH})_{2}$ treatment $(\mathrm{B})$, and after soaking in SBF for 7 days.

The presence of hydroxyl groups in the $\mathrm{EVOH}$ polymer surface enhances the reactivity of the organic substrate, which leads to an improved bonding between the substrate and the $-\mathrm{SO}_{3} \mathrm{H}$ groups. These groups acts as nucleating layer for the formation of the bonelike apatite after the $\mathrm{Ca}(\mathrm{OH})_{2}$ treatment. Also, by EDS analysis it was detected an appreciable quantities of $\mathrm{Ca}$ and $\mathrm{P}$ on the surface of both polymers. The obtained results demonstrated that the incorporation of $-\mathrm{SO}_{3} \mathrm{H}$ onto the surface of HMWPE and EVOH samples through sulfonation and their stabilization by soaking in a $\mathrm{Ca}(\mathrm{OH})_{2}$ saturated solution leads to the formation of an apatite layer. Moreover, as it can be observed after TF-XRD measurement, sulfonated samples without calcium treatment are not able to form apatite on their surface in SBF even after 7 days. It is speculated that the apatite-forming ability of $-\mathrm{SO}_{3} \mathrm{H}$ groups was significantly dependent on the incorporation of $\mathrm{Ca}^{2+}$ ions, which led to more stable $-\mathrm{SO}_{3} \mathrm{H}$ groups. By soaking in SBF for 7 days, these groups together with $\mathrm{Ca}^{2+}$ ions, leads to an increase of the ionic activity product of the apatite and as result accelerate the apatite nucleation. Previously work [7] has confirmed these results by means of an electrophoresis study. They have shown that the formation of bone-like apatite on bioactive polyethylene, which was produced by incorporation of $-\mathrm{SO}_{3} \mathrm{H}$ groups, in SBF is due to electrostatic interaction of the polymer surface and ions in the fluid. Such results indicated that the initialization of apatite nucleation involves an electrostatic interaction between the $-\mathrm{SO}_{3} \mathrm{H}$ and calcium ions.

\section{Conclusions}

The incorporation of $-\mathrm{SO}_{3} \mathrm{H}$ groups and their stabilization by soaking in a $\mathrm{Ca}(\mathrm{OH})_{2}$ saturated solution prove the validity of the proposed concept and show that they are effective on inducing apatite nucleation on the surface of these polymers. All these facts might allow for the development of apatite-polymer composites with similar structures to the living bone, with a great potential for being used on bone related applications.

\section{Acknowledgments}

I. B. Leonor thanks the Portuguese Foundation for Science and Technology (FCT) for providing her a PhD scholarship (SFRH / BD / 9031 / 2002). This work was partially supported by FCT through funds from the POCTI and/or FEDER programmes.

\section{References}

[1] T. Kokubo, H-M. Kim, M. Kawashita: Biomaterials 24 (2003), p. 2161.

[2] H.D. Park, W.K. Lee, T. Ooya, K.D. Park, Y.H. Kim, N. Yui: J. Biomed. Mater. Res. 60 (2002), p. 186. 
[3] D. Klee, R.V. Villari, H. Hocker, B. Dekker, C. Mittermayer: J. Mater. Sci. Mater. Med. 5 (1994), p. 592.

[4] G.T. Grasel, S.L. Cooper: J. Biomed. Mater. Res. 23 (1989), p. 311.

[5] T. Kokubo, H. Kushitani, S. Sakka, T. Kitsugi, T. Yamamuro: J. Biomed. Mater. Res. 24 (1990), p. 721.

[6] G. Socrates: Infrared characteristic group frequencies (John Wiley \& Sons, Chichester 1998).

[7] I. B. Leonor, H.-M. Kim, F. Balas, M. Kawashita, R. L. Reis, T. Kokubo and T. Nakamura: Bioceramics 17 (Trans Tech Publications, Zurich 2005), p. 453. 